\title{
How to Use E-Commerce Strategy to Add Value for Hotel Industry: A Case Study of 7 Days Inn
}

\author{
Yiqi Xiong \\ Department of Logistics and Information Management, Zhuhai College of Jilin University, Guangdong, China
}

\begin{abstract}
A continuing stream of innovation in technology and Internet are keeping transforming the world and business into a new stage. It is not surprising that e-commerce become the critical part in modern commercial society and it enables a lot of new products, services, and develop new business models, especially in some specific areas like hotel industry. A typical case of 7 Days Inn is used since it performs the best in terms of e-commerce strategy in the parallel industry to further explain each of the elements with explicit examples. After analyzing a successful e-commerce strategy, comparisons and recommendations are also given out to figure out what is the best way to add value for hotel service industry.
\end{abstract}

Keywords-e-commerce strategy; hotel service industry; 7 Days Inn

\section{INTRODUCTION}

7 Days Inn (SVN) is one of the three biggest economy hotels in mainland China, with its large market share, it also outraces others in parallel industry in terms of e-commerce strategies, and it builds an e-platform with state of art techniques. This is why we choose it as the case for further demonstration of how to use e-commerce strategies wisely and add value for hotel service industry.

In this paper, we category and extract the essences of the literatures that concerning the seven dimensions of an ecommerce strategy including four positional factors and three bonding ones.

\section{SEVEn Dimensions Of E-COMmerce Strategy}

\section{A. Leadership}

Core competitiveness of leadership can be inflected by the following parts.

1) Competitive position in the parallel industry

7 Days Group Holdings Limited (SVN), founded in 2005, listed on NASDAQ on Nov.20th, 2009, is the first Chinese hotel group that landed on the New York stock market. By now, 7 Days Inn has already had around 2000 branches in operation covering around 300 main cities in mainland China, and has already formed a national network of economy franchising hotel group.

2) Revenue status quo

A company's performance, especially the revenue is one of the benchmarks that can indicate whether it has a good leadership and direction of the board. For SVN, a total of 231 hotels were added in full single year 2010 and makes the number to a total of 568 hotels in operation. The total net revenue in the fourth quarter increased $41.4 \%$ year-over-year to RMB439.1 million and the adjusted EBITDA in a full year 2010 grew $51.9 \%$ year-over-year to RMB348.8 million. It is the best performed economy hotel group within the parallel industry in mainland China--the good performance can't be achieved without a good leadership.

3) Market share

Since 2003, economy hotel chains featured with convenient accommodation have emerged and keep expanding in China, gaining a growing customer base primarily businessmen and leisure travelers. According to the online travel booking website Kuxun, 7 Day's plan is proved to be very successful from the online hotel booking performance. Indicated by the statistics, 7 Day owned the largest share in the online hotels market, which was $9.97 \%$, almost $10 \%$ of the entire online hotel booking amount in 2014. Experts believe that in 2012, the first 3 giants (Home Inns, Han Ting and 7Day Inns) will occupy more than 70\% of the hotel share in mainland China.

\section{B. Infrastructure}

Once the need to develop e-commerce in some form had been identified, the single most important issue facing the executives and technologists charged with developing Internet-based projects is infrastructure.

1) Strategic level

7 Days Inn knows that high-tech and a comprehensive e-commerce strategy weight quite important in the hotel service industry, so they put a lot of emphasis on the establishment of the e-platform and optimize their networks at the most, thus can they cope with the challenges that will come to them later in the future as other competitors can win over them simply by a more sophisticated network service. Also, it is now trying to expand with the fastest pace since their business can grow with expansion and the progress of their services provided.

2) Organizational level

7 Days Inn has an innovative leadership that gives out the lasts challenges as well as the strategies that can cope with them; a service team that delivers the best services which give customers a good impression and create the WOM, they even create a standard service process and training system that ensures the best service among all the competitors; facilities need to be changed time by time and they also form their own sponsored wholesalers that can provide them the best products at the lowest price. 


\section{3) The execution occurs through the physical layer}

The hardware and software of the computing environment are in conjunction with the telecommunication infrastructure. 7 Days Inn's hardware generally include office automation system, enterprise resource management system, financial management system, supply chain management system, customer relationship management system and so on, which could be integrated through a variety of technologies. And its software system includes website--- via which the suppliers, procurement, partners and clients could visit all internal resources of the enterprise. Its major functions are distribution of business information, acceptance of customers' demands, and completion of online transactions. Suppliers, partners, procurement, distribution center, payment center, and CA system are the external entities of E-commerce system.

By using information technology, it has already built exclusive integrated networks and business systems, such as intranet system involving reservations system which combines the call Centre, short massage, mobile WAP, and Internet, hotel affairs management system and so on.

\section{Organizational Learning}

7 Days Inn has done very well in organizational learning. Organizational learning is very essential for an organization to learn and adapt to the new situation in ecommerce.

\section{1) Adopt new ideas}

7 Days Inn provides a platform in its website allowing customers to make complains and suggestion to reflect the existing problems. In this platform, the staffs constantly communicate with the customers, and would conduct the problem within 48 hours. All of the feedbacks from the customers would be assessed, and the useful information would be delivered to manager level to improve decisionmaking. Thus managers can adjust their existing strategy and planning based on these emerging problems as soon as possible. As a result, this platform not only attracts many people to visit its website to express their idea, but also enhances the 7 Days' brand reputation by creating effective mechanisms to meet customers' needs and handle them properly.

\section{2) Continue learning system}

7 Days Inn actively undertakes employee-training program. It gives up the traditional way of employee training; rather, it builds up a high-efficiency networktraining platform to allow every employee to learn without the geographical and temporal boundaries. 7 Days adopts a new learning development system named Smart Learning to gradually perfect the system of position learning. This platform is aimed at realizing information management of every single training process. Furthermore, 7 Days utilizes this learning platform to improve and perfect the assessment mechanism, Employee's training results would be examined, and they would timely receive their learning assessment, which could stimulate employee's learning motivation and strength their performance.

\section{Technology}

Technology leadership involves the early adoption of an emerging technology to achieve a preemptive position. It is an integral part of the overall leadership strategy.

1) High-tech information system to operate business

Using of IT technology management is one of the 7 days inn core strengths. Relying on "click and mortar" model, 7 days Inn set up one of the best E-commerce platform of hotel chain industry. Leading technology includes Central Reservation System (CRS), Material Requirement Manager, WAP timely confirmation system, SMS booking confirmation system and so on. All of these integrate a advanced system. Establishment of Central Reservation System encourages users to arrange rooms and business by themselves. All of these branches are made up the operating system of 7 days inn. According to this system, 7 days inn enhances their operational capability. Customers also can experience the convenience of this system. Another part of this system is internalsystem which includes these aspects: Material Requirement Manager, Enterprise Portal, Customer Relationship Management, Online Reimbursement system. According to this system, 7 days Inn could get the shop quality control, development of assessment, Financial Statements, Marketing Reports Operations Reports, Human Resource.

7 days Inn depends on self-designed powerful IT system, they could simultaneously monitor branches operating condition.

2) B2C model website analysis

Overall style of the website is concise and clear. It contains 8 sections: My 7 Days, 7 Days' products, Branch Booking, New Activity, 7 Days Forum, Tickets, Car Rental, Price index.

My 7 Days: Website provides two windows for different customers: Members Login and Cooperation Login;

7 Days' Products: The introduction of their Products, advantage;

Branch Booking: Customer need to click only 5 times which finish their online booking. (Inquiry $\rightarrow$ Choosing $\rightarrow$ Booking $\rightarrow$ Check $\rightarrow$ Payment $\rightarrow$ Success)

New Activity: Information of the newest promotions and membership benefits,

7 Days Club: Customer to customer communication. They could get useful information and make comments on branches of 7 days Inn.

Tickets \& Car rental: Additional services. This kind of one-stop service (tickets booking, room booking, car hire) save customers' time and make them feel convenient.

Price Index: Latest pricing information. Customer can contrast the price information of every branch in same city.

24 hours robot: Online service. Customers could ask questions by this method at any time.

\section{E. Service}

7 Days Inn advocated the brand concept "happy self, my life" and the spread the vision of make customers "sound sleep every day". It applies continuous integration and 
innovation on the design of product and service processes, and is committed to providing value-conscious business travelers with a clean, environmentally friendly, comfortable and safe accommodation services and member services to meet the accommodation needs of the core customers.

\section{1) Membership}

Financial report showed that in the first quarter of 2015, the members of 7 Days Inn was over 70 million. 7 Days Inn became the first branded economy hotel which has over 70 million members in China and continued to maintain this competitive advantage.

How to really know the customers is a central problem for businesses with millions of offline and online customers. 7 Days Inn exemplifies the use of information system and technologies to achieve customer intimacy. 7 Days Inn has introduced a number of member benefits, including regular member discount, a wealth of bonus points reward scheme, free milk before going to bed and breakfast.

\section{2) Customization}

7 Days Inn' e-service is more complicated, including the booking time and the after leaving communications, such as forum, emails and questionnaires. 7 Days Inn use information systems to keep track of guests' preferences, such as their preferred room temperature, check-in time, frequently dialed telephone numbers, and television programs, and store these data into a giant data repository. Individual rooms in the hotels are networked to a central network server computer so they can be remotely monitored or controlled.

\section{3) Provide convenient facilities and services}

As a leader in modern hotel industry with advanced ecommerce strategy, 7 Days Inn is one of the minority budget hotels who can provide a "7×24 hours" services, offering up to 5 kind of ordering methods, including online reservations, telephone reservation, recreate by WAP, SMS subscriptions and mobile client. Customers can use multiple channels to complete the room reservation, which is a full application of the e-commerce advantage. Through the network platform, customers can also complete the free membership registration, breakfast bookings, ticket booking, car rental, reservation of community assistance and other services.

\section{F. Branding}

7 Days has established its brand associated with low price and excellent service. 7 Days online booking system displays everyday low-cost pricing for all of the branch hotels around China, and its also inform the costumers which branch has the special offer and lowest price and other price promotion activities.

Moreover, 7 Days Inn has paid high attention to be remarkable enablers and amplifiers of the word of mouth. 7 Days has forum site for member sharing their services experiences, essence of life and humorous jokes. In addition, 7 Days has its Sina Weibo and WeChat Official Account in the most popular social network and try to make high-quality interactions with customers to build up and maintain their long-term relationship.

\section{G. Marketing}

7 Days Inn, adopting its innovative marketing strategies under the e-commerce environment to increasingly accelerate its development and expansion, is a specific and typical example for the analysis of e-commerce strategy, especially in the e-marketing aspect.

\section{1) Customer}

7 Days Inn strives to offer consistent and high-quality accommodations and services primarily to the growing population of value-conscious business and leisure travelers who demand affordable, clean, comfortable, convenient and safe lodging, and to respond to consumers' needs. 7 Days Inn obeys the "customer experience first" philosophy to consistently identify the target consumers and to provide personalized service.

\section{2) Cost}

In order to offer reasonable and relatively low price to customers, 7 Days Inn spares no effort to control cost in hardware configuration through rejecting to set large wardrobes, heavy desks, and design luxury bathrooms. On the contrary, the unique style of 7 Days Inn is simple, clean, convenient, warm, which attaches importance to practicality and standardization. Meanwhile, in the process of making room price, 7 Days Inn decides to eliminate one-time wash supplies and gives consumers freedom to choose what they need when they are booking rooms on the e-commerce platform.

\section{3) Convenience}

7 Days Inn has always been concerned with the customer convenience in every aspect. On one hand, 7 Days Inn hotels, normally, are located in downtowns or areas which are near bus tops and convenient to get to the railway station or airport. Meanwhile, bright yellow appearance and 7 in large size of every 7 Days Inn building have become a unique symbol for customers to find much easily. On the other hand, it is a great success to create and apply the advanced and sophisticated e-commerce platform for the convenience of both customers and 7 Days Inn itself. Also, the successful e-commerce platform integrates Internet, call center, SMS, WAP and shop management system. So customers are able to make a real time search and inquiry, reservation, confirmation and payment, which not only from convenient ways for customers but also reduce the cost of human resource in 7 Days Inn and the time of processing orders around China. According to Alexa.com, an Internet information company that tracks website traffic, 7 Days Inn had the top ranked website for Internet traffic among Chinese economy hotel chains.

\section{4) Communication}

Absolutely, it is significant for 7 Days Inn to enhance communication with customers and share different experiences. As for online communication, 7 Days Inn has called for increasing members to register and experience 7 Days-style service on the e-commerce platform, and developed several encouragement activities like 77yuan for 
first check-in for new members. At the same time, 7 Days Inn invites members to accomplish questionnaires after check-out to share their feelings and seek first-hand feedback for further improvement. What's more, there is a membership forum, 7 Days Club, designed for customers to be free to discuss their experience and for 7 Days Inn to release the latest events and monitor member's suggestions. 7 Days Club helps build customer loyalty, minimize costs by promoting the e-commerce platform's various electronic reservation channels, and improve the quality of accommodations and services.

\section{CONCLUSIONS}

We wish to enumerate how 7Days' operation mode and cast it into a uniform framework with systematic ecommerce strategy. This alone we feel to be worthwhile, and we believe that others will find our explanations and formulations useful and worth adoption.

As a listed company, 7 Days Inn now has the ability to explore the market outside main-land China. They can use the strategy we discussed above but need to change its plan according to different situations. For instance, if 7 Days Inn wants to set the branches in some tourist attraction area, they should concentrate more on the service than the price. If the branches located near the station, low price may become the first choice.

Based on the successful experience of 7 days Inn, we get the conclusion that if the economy-chain hotels want to continue to maintain the high growth, they must be concentrate more on products, services, human resource management, marketing and business model innovation. They should pay more attention to strengthening cost control, increase the intensity of branding and cultural construction, and select the appropriate financing and expansion strategy.

\section{REFERENCES}

[1] Ali Acilar, Çaglar Karamasa. 2012. Factors Affecting the E-Commerce Adoption by Small Hotels: A Comparative Case study. International Journal of E-Adoption 4(1): 1-10

[2] James N.K. Liu. Elaine Yulan Zhang 2014. An Investigation of Factors Affecting Cutomer Selection of Online Hotel Booking Channels. International Journal of Hospitality Management 39:71-83

[3] Liang Xu, Xiaoyan Xu. 2014. A Decision Problem of Hotels on Setting Online-Exclusive-Rooms in E-Commerce Age. Journal of Service Science and Management 7(4): 323-336 